\title{
Bubble dynamics in nucleate pool boiling on micro-pin-finned surfaces in microgravity
}

\author{
Yonghai Zhang ${ }^{a}$, Jinjia Wei ${ }^{a}{ }^{a}$, Yanfang Xue ${ }^{a}$, Xin Kong ${ }^{a}$, Jianfu Zhao ${ }^{b}$ \\ a State Key Laboratory of Multiphase Flow in Power Engineering, Xi'an Jiaotong University, Xi'an 710049, China \\ ${ }^{\mathrm{b}}$ Key Laboratory of Microgravity (National Microgravity Laboratory)/CAS, Institute of Mechanics, Chinese Academy of Sciences, Beijing 100190, China
}

\section{H I G H L I G H T S}

- We performed micro-pin-finned surface in pool boiling in microgravity.

- Bubble behaviors on micro-pinfinned surface in microgravity were analyzed.

- A new bubble departure radius prediction model on micro-pin-fins in $\mu \mathrm{g}$ was developed.

- Both bubble force balance and bubble coalescence are considered in the model.

- The predictions agree much better with the experimental data than force balance model.

\section{A R T I C L E I N F O}

\section{Article history:}

Received 30 October 2013

Accepted 29 April 2014

Available online 9 May 2014

\section{Keywords:}

Pool boiling

Bubble dynamic

Micro-pin-fins

Microgravity

Bubble departure radius

Model
G R A P H I C A L A B S T R A C T
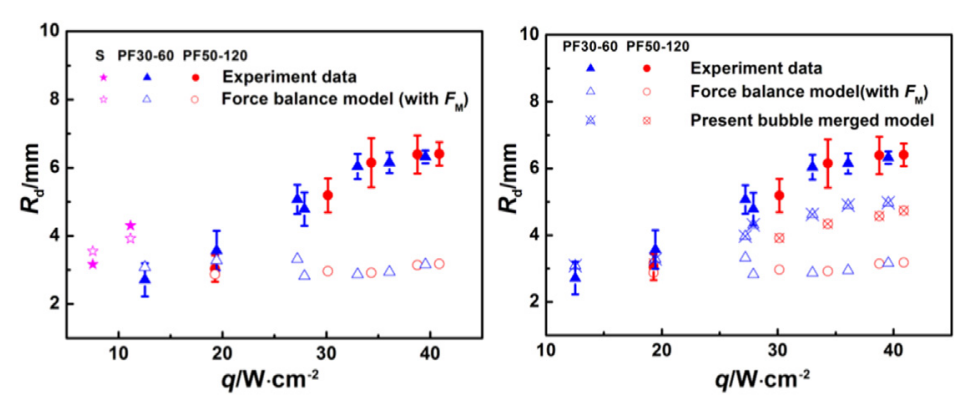

\section{A B S T R A C T}

Bubble dynamics is an important phenomenon, which basically affects the nucleate boiling heat transfer coefficient. Nucleate boiling heat transfer of gas-saturated FC-72 on micro-pin-finned surface was experimentally investigated in microgravity environment by utilizing the drop tower facility in Beijing. The dimensions of the silicon chips were $10 \mathrm{~mm} \times 10 \mathrm{~mm} \times 0.5 \mathrm{~mm}$ (length $\times$ width $\times$ thickness) on which two kinds of micro-pin-fins with the dimensions of $30 \times 30 \times 60 \mu \mathrm{m}^{3}, 50 \times 50 \times 120 \mu^{3}$ (width $\times$ thickness $\times$ height, named PF30-60, PF50-120) were fabricated by the dry etching technique. The experimental data were presented for the bubble departure radius on micro-pin-finned surface. Experimental results showed that the bubble detachment radius increases with increasing heat flux, but the traditional force balance model failed to predict the bubble detachment radius on micro-pin-finned surfaces especially at high heat fluxes. Therefore, a new modified model for predicting bubble departure radius on micro-pin-finned surface in microgravity was developed. In this model, both bubble force balance and bubble coalescence are considered as two main factors influencing the size of bubble departure radius, and the predictions agree much better with the experimental data at moderate and high heat fluxes than the force balance model.

(c) 2014 Elsevier Ltd. All rights reserved.

\footnotetext{
* Corresponding author. Tel.: +86 02982664462.

E-mail address: jjwei@mail.xjtu.edu.cn (J. Wei).
}

\section{Introduction}

Nucleate pool boiling heat transfer is widely used in desalination, chemical, petrochemical, refrigeration and power plants owing to the very high heat transfer coefficient, compared with those of other heat transfer methods. Previous studies showed that 
micro-pin-finned surface enhances boiling heat transfer in both normal gravity and microgravity [1-4]. It can be seen from the experimental research that the bubble departure radius is very important for determining the boiling heat transfer efficiency during nucleate pool boiling. In microgravity, bubble growth and departure radius directly influence the occurrence of steady nucleate boiling period.

A large number of studies on bubble growth rate and departure radius have been reported in the literature. Many famous correlations were developed for predicting the bubble radius under nucleate pool boiling condition for different applications. The earliest known relation for the bubble departure radius was given by Fritz [5], which the bubble departure is governed by buoyancy forces and surface tension forces. The relation between bubble frequency and diameter during nucleate pool boiling was studied by Mcfadden and Grassmann [6]. From a dimensional analysis coupled with available experimental data a new relationship was developed. Cole and co-workers [7-9] have conducted a series of studies on bubble growth and departure at subatmospheric pressures, the bubble departure diameter was correlated with the Jakob number in their theory. Gorenflo et al. [10] correlated bubble departure diameter at high heat fluxes when inertia becomes important. A new model was proposed for the prediction of vapor bubble departure diameters in saturated pool boiling by Zeng et al. [11]. They considered that the vapor bubble growth rate is a necessary input to the model, and its reliable estimation was required to predict accurately departure diameters. A characteristic length scale and a time scale were proposed to describe the dynamic growth and departure process of bubbles by Yang et al. [12]. A correlation between bubble departure diameter and bubble growth time was established, and a prediction formula for bubble departure diameter was suggested by considering the analog between nucleate boiling and forced convection. As illustrated above, most of correlations are applied in gravity condition. Even after extensive research spanning more than half a century, there is no generalized correlation for bubble diameter at departure due to the complexity of the boiling phenomena.

For boiling heat transfer in microgravity, there are still some correlations to predict the bubble radius. The effect of gravity on the bubble dynamics for saturated pool boiling of water and $60 \%$ sucrose have experimentally studied by Siegel and co-workers [13,14]. Meanwhile, bubble departure radii were measured. The experimental data were compared with the predicted bubble departure radii obtained through Fritz [5] and Zuber [15] model. As concluded, the experimental results were in good agreement with Fritz's correlation [5] for saturated pool boiling of water in microgravity $\left(<10^{-1} g_{0}, g_{0}=9.81 \mathrm{~m} \mathrm{~s}^{-2}\right)$, indicating that bubble detachment mainly depends on buoyancy and surface tension forces. While $10^{-1} g_{0}<\mu \mathrm{g}<1 g_{0}$, the experimental results were in good agreement with Zuber's correlation [15], indicating that there are other dynamic forces, except for buoyancy and surface tension forces, pull the bubble to detach from the heater. For 60\% sucrose, the results were very different from those of the saturated pool boiling of water. The bubble departure radius is almost constant though with changing gravitational acceleration. By using a force balance model, the bubble departure radius on smooth surface was estimated and compared with that from experimental measurements on literature in microgravity, conducted by Karri [16], and the results were in good agreement with the experimental micro-g data of Siegel and Keshock [13].

Dynamic force and static force balances were applied by Lee [17] to analyze bubble departure process on a flat plate and on a thin wire. The results showed that the dominating forces are the pressure force, surface tension force and buoyancy force exist in cases when the contact angle was larger than $39.5^{\circ}$. In case the contact angle was smaller than the above value, buoyancy force was not essential to the departure process. The value of bubble departure radius in microgravity approaches to a constant, or have no solution for asymptotic growth period. As for the thin wire, if the bubble departure radius was much larger than the wire radius, the dominating factors were the drag force and the pressure force. In case a valid solution exists, the bubble departure radius in microgravity approaches to a constant.

In all models mentioned above, the Marangoni effect was ignored. Recently, considering Marangoni effect, a mechanistic model of bubble departure was presented by Zhao et al. [18] to reveal the mechanism for pool boiling on wires in microgravity. The predictions were in qualitative consistency with the experimental observations. However, the usage of the boiling heat transfer model is limited due to the complexity of boiling heat transfer, difficulties in determination of parameters and calculation of bubble departure radius. At present, the most common used method is for analyzing the bubble force balance, before establishing a departure criterion and calculating the departure radius. As the above model requires no heating surface microstructure to be considered, the model is not suitable for cases involving micro-pin-fins. In this paper, we develop a model for calculating bubble departure radius on micropin-finned surface in microgravity.

\section{Experimental apparatus and test procedure}

\subsection{Experimental apparatus}

The pool boiling test facility system designed for conducting drop-tower experiments is shown schematically in Fig. 1. The $100 \mathrm{~mm} \times 100 \mathrm{~mm} \times 100 \mathrm{~mm}$ boiling chamber made of polycarbonate for visualizing boiling phenomena, is filled with about $1 \mathrm{~L}$ air-dissolved $\mathrm{FC}-72$, the test liquid, at saturation temperature $\left(T_{\text {sat }}\right)$ of $56{ }^{\circ} \mathrm{C}$ and under atmospheric pressure. A rubber bag attached to the test vessel is used to maintain a near-atmospheric pressure. By this way, subcooling $\left(\Delta T_{\text {sub }}\right)$ and pressure $\left(P_{\mathrm{s}}\right)$ conditions can vary during the experiments. The bubble behavior is videoed by using a $25 \mathrm{~Hz}$ CCD camera installed in front of the test vessel at a direction angle towards to the heater surface for visual observation. Simultaneously, a high speed digital camera (VITcam

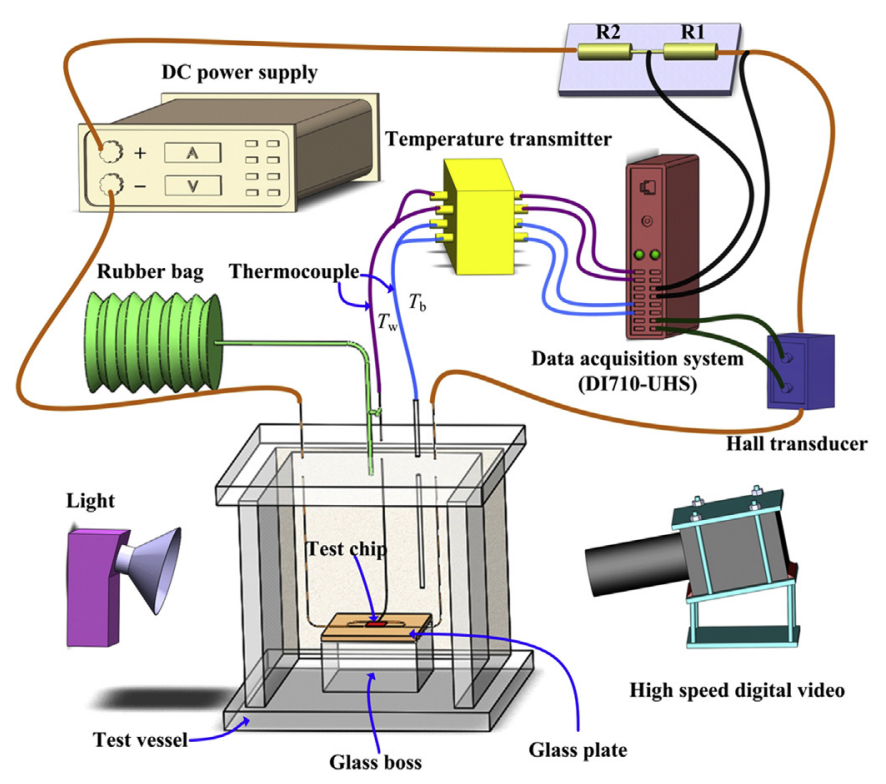

Fig. 1. Schematic diagram of the experimental apparatus. 
CTC) imaging 500 frames per second at a resolution of $1024 \times 640$ pixels, with a shutter speed of $1 / 2000 \mathrm{~s}$ is adopted together with lens (Computar MLM-3XMP) to image the boiling phenomena. A programmable DC power supply is connected in parallel connection to two series resistances $\left(R_{1}=5 \mathrm{k} \Omega\right.$, $R_{2}=100 \mathrm{k} \Omega$ ) and the test chip. The two series resistances are used to measure the heating voltage $(U)$ across the silicon chip in the circuit. Thus, the heating power is calculated based on constant heating current $(I)$ and voltage measured across the test chip, and the current is measured by a hall transducer and then the data is transmitted to a data acquisition system.

A 0.13-mm-diameter T-type thermocouple for local wall temperature $\left(T_{\mathrm{w}}\right)$ measurement is bonded at center of the bottom surface of the test chip using high thermal conductivity epoxy adhesive, and the detailed heater structure are shown in Fig. 2(a). The local temperature of bulk liquid $\left(T_{\mathrm{b}}\right)$ is measured by a $0.3-\mathrm{mm}$ diameter T-type thermocouple positioned about $20 \mathrm{~mm}$ from the edge of the test chip and $40 \mathrm{~mm}$ above the chip level, to avoid being affected by bubble dynamics. The change of measured temperature of bulk liquid is less than $0.5 \mathrm{~K}$ during every test run about $90 \mathrm{~min}$. The two thermocouples to measure liquid and wall temperatures are connected to a temperature transmitter, so that voltage signals are collected by a data acquisition system (DI710-UHS), as shown in Fig. 1.

A P-doped N-type square silicon chip $\left(10 \times 10 \times 0.5 \mathrm{~mm}^{3}\right)$ is used for the heater element. The details of test section are shown in Fig. 2(b). Micro-pin-fins are fabricated on the chip surface to enhance boiling heat transfer by using dry etching technique. The
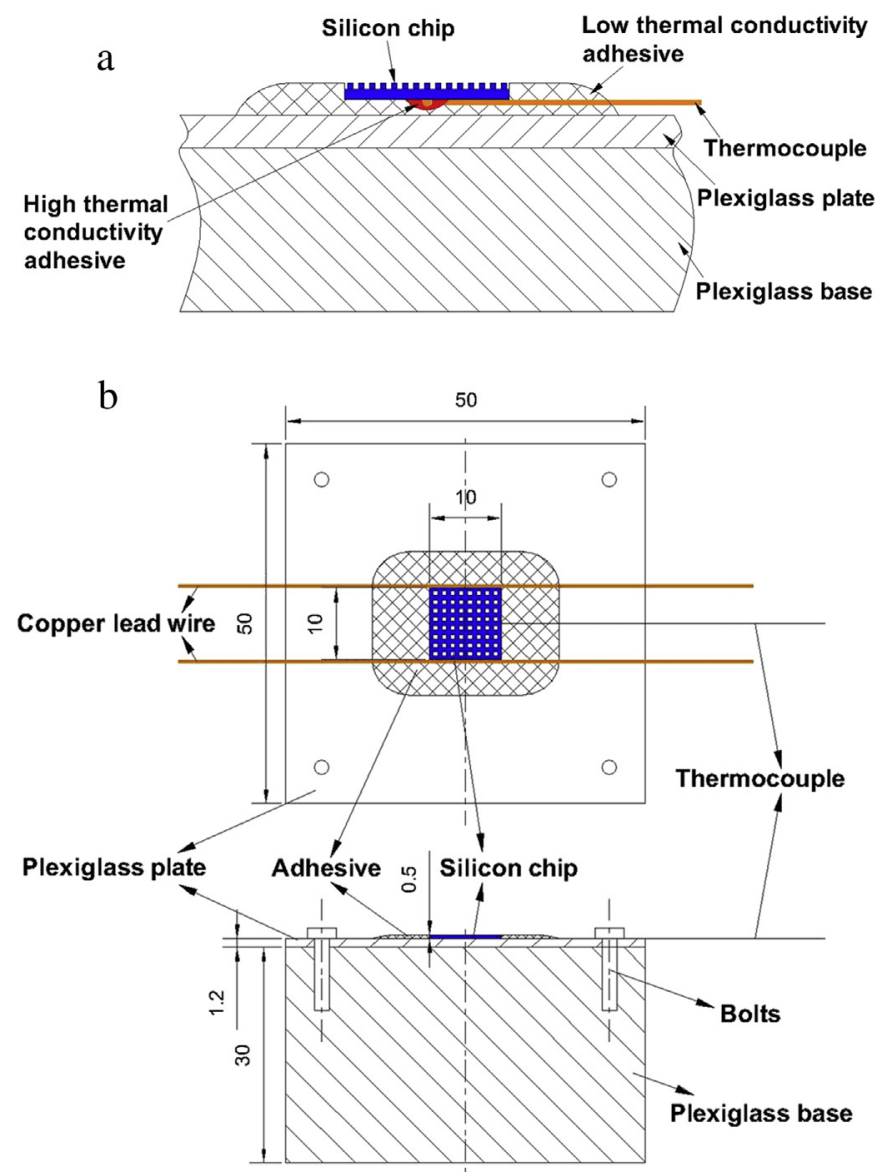

Fig. 2. Schematic diagrams of heater structure and test section (a) the heater structure (b) the test section. fins are $30 \mu \mathrm{m}, 50 \mu \mathrm{m}$ thick and $60 \mu \mathrm{m}, 120 \mu \mathrm{m}$ high respectively (denoted as PF30-60, PF50-120). A smooth chip (denoted as chip S) is also tested for comparison, and the SEM images of micro-pin-fins are shown in Fig. 3. The specific resistance is $1-3 \Omega \mathrm{cm}$, and the thermal conductivity $k$ is about $120 \mathrm{~W} \mathrm{~m} \mathrm{~W}^{-1} \cdot \mathrm{K}^{-1}$. The chip is Joule heated by a direct current. Two $0.25 \mathrm{~mm}$ diameter copper wires are soldered to the side surfaces at the opposite ends of test chip to supply power for the chip. In order to secure the ohmic contact between the semiconductor silicon chip and the copper wire, a special solder with a melting point at $300{ }^{\circ} \mathrm{C}$ is applied for the silicon chip through ultrasonic bonding method before soldering the copper wires. The test chip is bonded on a $50 \times 50 \times 1.2 \mathrm{~mm}^{3}$ plexiglass plate by using epoxy adhesive and then fixed on the plexiglass base bonded on the bottom of the test vessel, which facilitates the exchange of the silicon chip. The side surfaces of the chip are covered with an adhesive with very small thermal conductivity of $0.12 \mathrm{~W} \mathrm{~m}^{-1} \cdot \mathrm{K}^{-1}$ to minimize heat loss. Therefore, only the upper surface of the chip is effective in heat transfer. Besides, the substrate is made of plexiglass and the thermal conductivity of plexiglass is about $1.0886 \mathrm{~W} \mathrm{~m} \mathrm{~m}^{-1} \cdot \mathrm{K}^{-1}$ that does not vary with temperature.

The uncertainties in chip and bulk liquid temperatures measured by the thermocouples are estimated to be less than $0.3 \mathrm{~K}$. Wall temperature uncertainty may result in errors due to thermocouple calibration by using a platinum resistance thermometer $(0.03 \mathrm{~K})$, temperature correction for obtaining surface temperature based on the measured value at the bottom of the chip $(0.2 \mathrm{~K})$, temperature unsteadiness $(0.1 \mathrm{~K})$ and thermocouple resolution (less than $0.1 \mathrm{~K}$ ). Heat flux uncertainty is consisted of the errors of electric power per unit area supplied to the chip, heat loss ratio through substrate conduction and transient effect ratio due to the change of internal energy of chip, respectively. Measurement errors of heat voltage $U$, current $I$ and side length $l$ are $0.1 \%, 0.014 \%$ and $0.5 \%$, respectively. The heat loss ratio through substrate is about $5.0 \%$ and the transient effect ratio is about $0.3 \%$. So the uncertainty in heat flux is estimated as approximately $6 \%$ for steady boiling heat transfer and $6.3 \%$ for quasi-steady boiling heat transfer. In addition, due to the effect of non-condensable gas on boiling curve, a quantitative comparison was performed in our ground experiments $[19,20]$ revealing that the existence of the dissolved gas reduces the boiling incipient wall superheat and increases the heat flux in low heat flux region. However, the effect of dissolved gas in nucleate boiling region at high heat fluxes can be ignored.

\subsection{Test procedure}

Experiments are conducted under the influence of terrestrial gravity before releasing the drop capsule and then in short-term microgravity during free falling in the drop tower in the National Microgravity Laboratory, Chinese Academy of Sciences, Beijing. The facility satisfied the safety criteria to expose the apparatus in the drop capsule in different gravitational environments varying between microgravity $\left(\mu \mathrm{g}\right.$ ) (about $10^{-2} g_{0}$ ) in the free falling period and high-g level in the deceleration recovery system $\left(16 g_{0}\right)$, and $\mu \mathrm{g}$ and $g_{0}$ are the gravitational acceleration in microgravity and under terrestrial conditions respectively.

The test chip is heated by setting a constant input current or voltage for the desired heat flux $q$ to initiate boiling on the heater surface. When the heat transfer reached to a steady state in about 4 min confirmed by the wall temperature, the free falling of drop capsule started which provided approximately $3.6 \mathrm{~s}$ effective microgravity environment. The high-speed digital camera could work for $8 \mathrm{~s}$ to capture the boiling heat transfer phenomena when an external trigger signal is received. Simultaneously, data measurement and video recording are conducted. As technical reform 

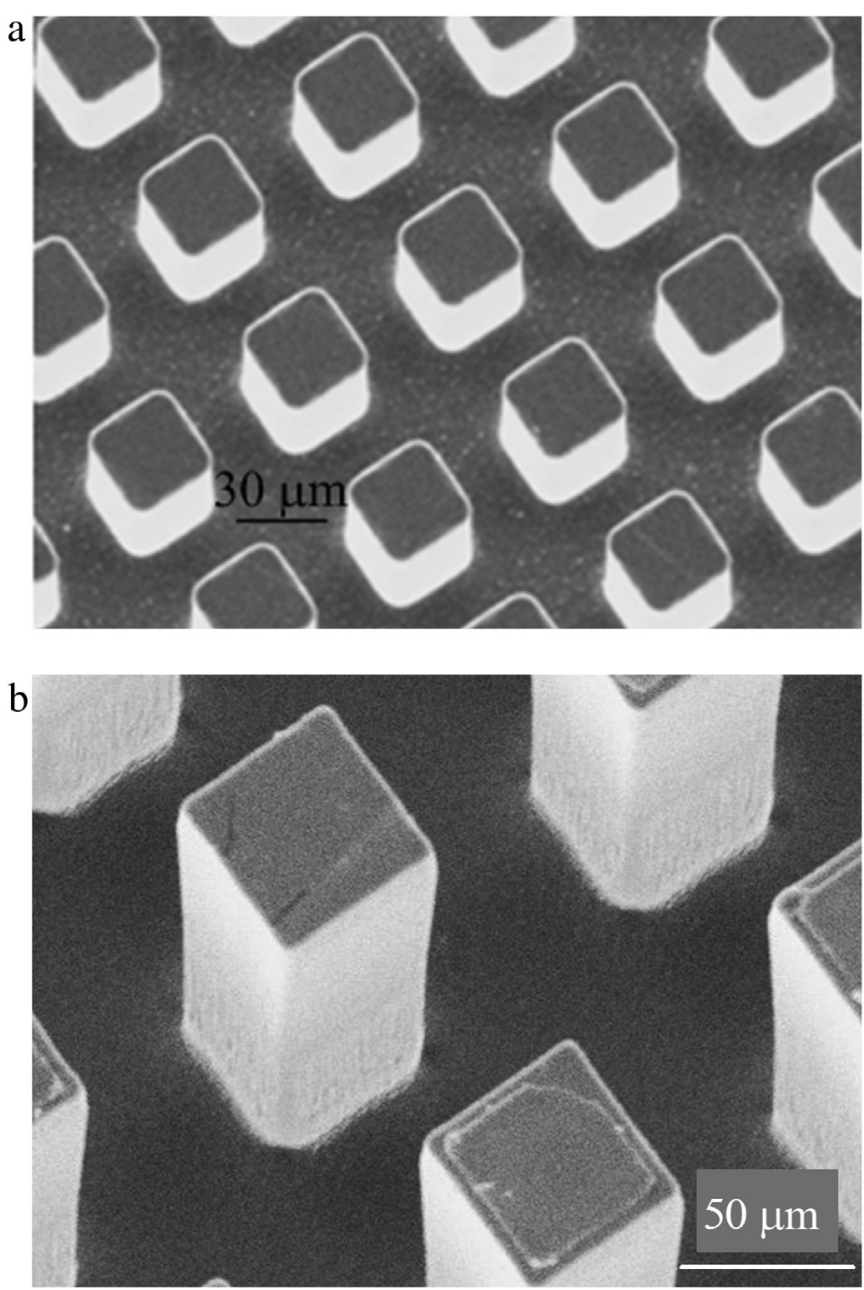

Fig. 3. SEM image of micro-pin-fins (a) PF30-60 (b) PF50-120.

on the drop tower in Beijing, the experiments are divided into two stages. In the first stage before technical reform, constant direct current method is adopted to heat the silicon chip. After that, in order to attain CHF in microgravity, the heating method with constant heating voltage is used to avoid chip damage. As experimental opportunity limited, only one run is conducted for one heat flux. In addition, to ensure the reproducibility and reliability of the data, identical ground experiments are also conducted for comparison, and the operating conditions are almost identical for both normal gravity and reduced gravity.

\subsection{Method of experimental data analysis}

The statistical data of bubble departure radius from experimental results can be analyzed by the following steps.

Step 1 Video of the bubble behavior by employing a high speed digital camera is saved in BMP format.

Step 2 Find out the corresponding bubble detachment pictures. The Matlab software is employed to read picture. According to the image pixels, the coordinate $y_{\text {-up }}, y_{\text {-down }}$ in the vertical direction, and coordinate $x_{\text {-left }}, x_{\text {-right }}$ in horizontal direction of the instantaneous detachment bubble are calculated.

Thus, the bubble radii in horizontal and vertical directions are expressed as follows:
$R_{x}=\frac{x_{- \text {right }}-x_{- \text {left }}}{2}$

$R_{y}=\frac{y_{- \text {up }}-y_{- \text {down }}}{2}$

Then, the average bubble departure radius is expressed as follow:

$R_{\mathrm{d}-\mathrm{ave}}=\sqrt{\frac{R_{x}^{2}+R_{y}^{2}}{2}}$

\section{Results and discussions}

Fig. 4 shows boiling heat transfer curves chip PF30-60 and PF50120 under different gravity conditions at atmosphere pressure. The boiling curves of chip S under different gravity conditions [21] are also shown for comparison. By the way, the liquid subcooling for smooth surface experiment is about $41 \mathrm{~K}$ (corresponding to $15^{\circ} \mathrm{C}$ of bulk liquid temperature) which is also caused by ambient temperature. The detail experimental conditions are summarized in Tables $1-3$. Due to the limited experimental opportunity, only one run was conducted for one heat flux. For chip PF30-60, eight run tests under microgravity conditions at eight different heat fluxes respectively are carried out with two heating methods. One is the constant heating current method in the low heat fluxes region of $7.2-27.2 \mathrm{~W} / \mathrm{cm}^{2}$ for the first four cases listed in Table 2, another is the constant heating voltage method for the last four cases in Table 2 as heat fluxes exceed $27.2 \mathrm{~W} / \mathrm{cm}^{2}$. We could not control the same temperature condition of working fluid at different experiments, because there is no preheater and no temperature control for working fluid system. The liquid subcooling of FC-72 corresponding to the above mentioned two heating methods are 43 and $32 \mathrm{~K}$, respectively, which is determined by the ambient temperature. For chip PF50-120, seven run tests under microgravity conditions at seven different heat fluxes respectively are also carried out with two heating methods. As shown in Table 3, the chip in the low heat fluxes region of $6.4-10.1 \mathrm{~W} / \mathrm{cm}^{2}$ is heated by the constant heating current method, the others are heated by the constant heating voltage method. The liquid subcooling of FC-72 corresponding to the above mentioned two heating methods of PF50120 are 43 and $31 \mathrm{~K}$, respectively.

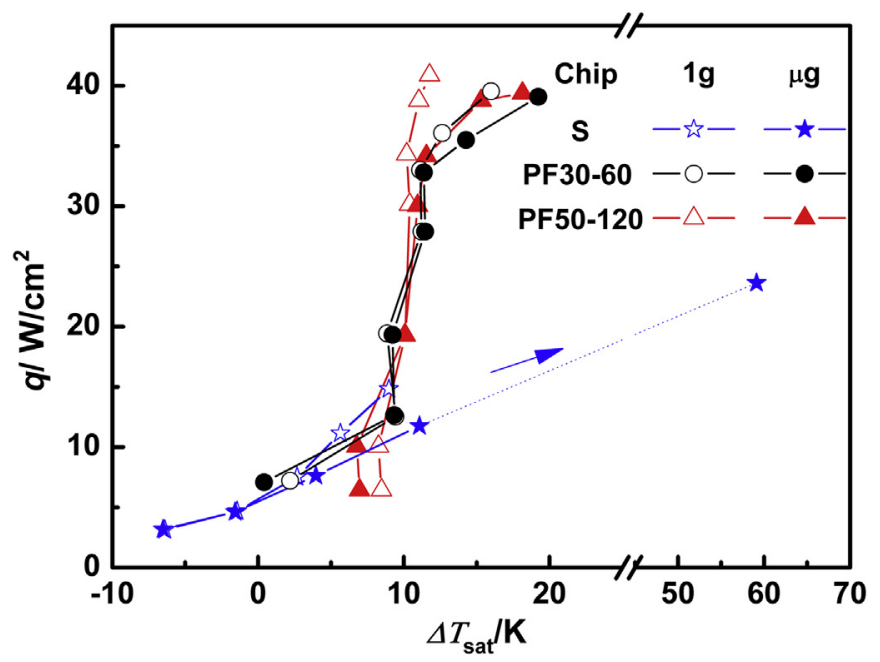

Fig. 4. Boiling heat transfer curves in microgravity. 
Table 1

Experimental conditions of the smooth surface in microgravity.

\begin{tabular}{|c|c|c|c|c|c|}
\hline Run\# & Pressure $P_{\mathrm{s}}(\mathrm{kPa})$ & Subcooling $\Delta T_{\text {sub }}(\mathrm{K})$ & Heating voltage $U(\mathrm{~V})$ & Heat flux $q\left(\mathrm{~W} \mathrm{~cm}^{-2}\right)$ & Heating current $I(\mathrm{~A})$ \\
\hline SI0.20 & 102.2 & 40.7 & 16.9 & 3.3 & 0.20 \\
\hline SI0.24 & 101.9 & 41.4 & 20.1 & 4.7 & 0.24 \\
\hline SI0.30 & 101.7 & 40.0 & 24.7 & 7.4 & 0.30 \\
\hline SI0.36 & 102.6 & 41.4 & 32.3 & 11.6 & 0.36 \\
\hline SI0.40 & 102.7 & 40.9 & 36.3 & 14.5 & 0.40 \\
\hline
\end{tabular}

Table 2

Experimental conditions of chip PF30-60 in microgravity.

\begin{tabular}{|c|c|c|c|c|c|}
\hline Run\# & Pressure $P_{\mathrm{s}}(\mathrm{kPa})$ & Subcooling $\Delta T_{\text {sub }}(\mathrm{K})$ & Heating voltage $U(\mathrm{~V})$ & Heat flux $q\left(\mathrm{~W} \mathrm{~cm}^{-2}\right)$ & Heating current $I(\mathrm{~A})$ \\
\hline PF3060I0.26 & 103.4 & 44.5 & 27.7 & 7.2 & 0.26 \\
\hline PF3060I0.34 & 102.9 & 42.2 & 36.9 & 12.5 & 0.34 \\
\hline PF3060I0.42 & 103.4 & 44.3 & 46.3 & 19.4 & 0.42 \\
\hline PF3060I0.50 & 103.3 & 44.2 & 54.4 & 27.2 & 0.50 \\
\hline PF3060U55 & 101.7 & 30.4 & 55.0 & 27.9 & 0.51 \\
\hline PF3060U60 & 100.7 & 32.4 & 60.0 & 33.0 & 0.55 \\
\hline PF3060U63 & 100.7 & 31.3 & 63.0 & 36.1 & 0.57 \\
\hline PF3060U66 & 100.9 & 32.1 & 66.0 & 39.5 & 0.60 \\
\hline
\end{tabular}

As is well known, the bubble behaviors are very different from each other between normal gravity and microgravity due to the lack of buoyancy force under microgravity condition. However, we can see that micro-pin-fins still show a large enhancement on boiling heat transfer compared with smooth surface in microgravity from Fig. 4. $\Delta T_{\text {sat }}$ is the difference between $T_{\mathrm{w}}$ and $T_{\text {sat. }}$. Under the low heat flux condition, vapor bubbles increase in size and are still attached to heater surface throughout the entire microgravity period. However, the wall temperature is a little lower than that in normal gravity, showing a heat transfer enhancement in microgravity. Under the moderate heat flux condition, with increase in heat flux, the number of vapor bubbles as well as their size significantly increases, the transition between low and high heat flux regions can be observed, and the wall temperature of chip is nearly consistent at different gravity levels. Moreover, coalescence occurs continuously among adjacent bubbles and the large coalesced bubble engulfs the small bubbles around it, resulting in the large coalesced bubble's departure from the heater surface eventually. At high heat fluxes, although the large coalesced bubble can also depart from the heater surface and the wall temperature is a little bit higher than that in normal gravity, it indicates that boiling heat transfer in microgravity is deteriorated as compared with that in normal gravity. Compared with the smooth surface, pool boiling heat transfer over micro-pin-finned surfaces has a lot of advantages including increase in heat transfer area and reduction of thermal resistance, and thus improving the heat transfer coefficient and CHF in terrestrial experiments in our previous study [22]. In the high heat flux region, although the micro-pin-finned surfaces are covered with large bubbles, the capillary force generated by the bubbles drives plenty of fresh liquid into contact with the superheated wall for vaporization through the regular interconnected structures, as well as improves the micro-convective heat transfer by the motion of liquid around the micro-pin-fins.

Fig. 5 shows bubble behavior of smooth surface and micro-pinfins under different heat fluxes in microgravity. For smooth surface, bubble behaviors in developing and fully developed nucleate boiling regimes at different gravity levels have been reported by Xue et al. [21]. For SI0.20 and SI0.24 responding to the heat fluxes of $3.1 \mathrm{~W} / \mathrm{cm}^{2}$ and $4.7 \mathrm{~W} / \mathrm{cm}^{2}$ on smooth chip, the bubbles attached to the heater surface during the whole microgravity period as shown in Fig. 5(a). For the heat fluxes of $7.5 \mathrm{~W} / \mathrm{cm}^{2}$ and $11.2 \mathrm{~W} / \mathrm{cm}^{2}$, only one big bubble departs from heat surface for both cases during $3.6 \mathrm{~s}$. For the heat flux of $14.8 \mathrm{~W} / \mathrm{cm}^{2}$, a coalesced large bubble forms rapidly and then covers the heater surface completely during the whole microgravity period, which prevents the fresh bulk liquid from accessing the heating surface for evaporation heat transfer, making the removal of heat flux very difficult and leading to an obvious increase of the mean heater surface temperature and deterioration of boiling heat transfer as shown in Fig. 5(a). As a result, only bubble departure radii of $7.5 \mathrm{~W} / \mathrm{cm}^{2}$ and $11.2 \mathrm{~W} / \mathrm{cm}^{2}$ are analyzed. For PF3060I0.26, PF50120I0.22 and PF50120I0.28 responding to the heat fluxes of $7.2 \mathrm{~W} / \mathrm{cm}^{2}$ on chip PF30-60 and the heat fluxes of $6.4 \mathrm{~W} /$ $\mathrm{cm}^{2}$ and $10.1 \mathrm{~W} / \mathrm{cm}^{2}$ on chip PF50-120, the bubbles also attached to the heater surface during the whole microgravity period (3.6 s) as shown in Fig. 5(b) and (c). For the other heat fluxes on micro-pinfinned surface of chip PF30-60 and PF50-120, big bubbles can depart from heat surface continuously during $3.6 \mathrm{~s}$, and the bubble departure radii of micro-pin-fins are analyzed by employing the same method as that for smooth surface.

Fig. 6 shows experimental data of the average bubble departure radius of smooth surface and micro-pin-fins under different heat fluxes in microgravity. The average bubble departure radius can be

Table 3

Experimental conditions of chip PF50-120 in microgravity.

\begin{tabular}{|c|c|c|c|c|c|}
\hline Run\# & Pressure $P_{\mathrm{s}}(\mathrm{kPa})$ & Subcooling $\Delta T_{\text {sub }}(\mathrm{K})$ & Heating voltage $U(\mathrm{~V})$ & Heat flux $q\left(\mathrm{~W} \mathrm{~cm}^{-2}\right)$ & Heating current $I(\mathrm{~A})$ \\
\hline PF50120I0.22 & 103.4 & 43.5 & 29.3 & 6.4 & 0.22 \\
\hline PF50120I0.28 & 103.4 & 42.3 & 36.1 & 10.1 & 0.28 \\
\hline PF50120U48 & 100.6 & 30.0 & 48.0 & 19.3 & 0.40 \\
\hline PF50120U60 & 100.8 & 31.8 & 60.0 & 30.2 & 0.50 \\
\hline PF50120U64 & 100.4 & 29.6 & 64.0 & 34.3 & 0.53 \\
\hline PF50120U68 & 100.8 & 32.1 & 68.0 & 38.8 & 0.57 \\
\hline PF50120U70 & 100.6 & 29.7 & 70.0 & 40.9 & 0.59 \\
\hline
\end{tabular}



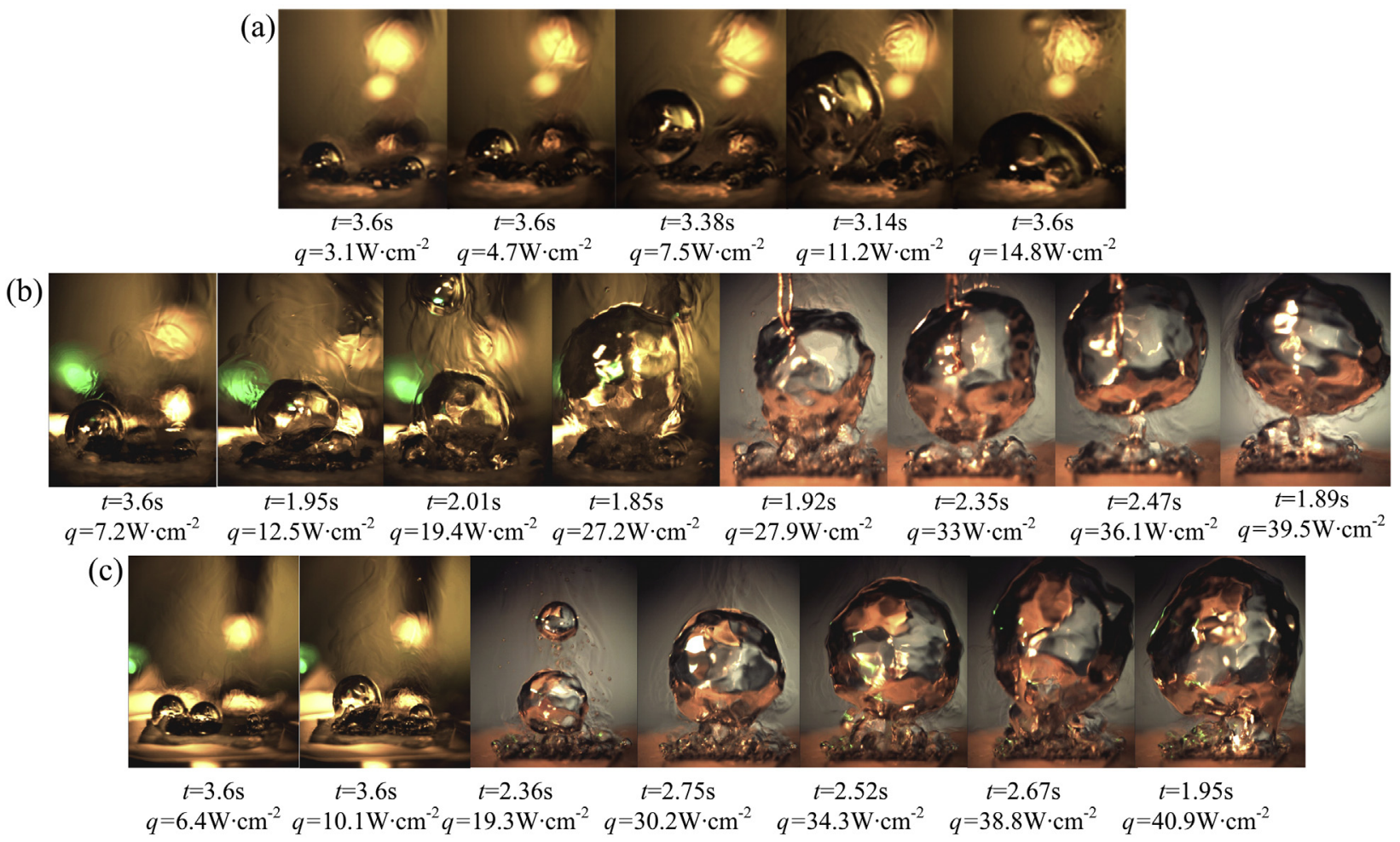

Fig. 5. Bubble behavior under microgravity and different heat fluxes: (a) chip S, (b) chip PF30-60, (c) chip PF50-120.

used as experiment bubble departure radius. It can be seen that the average bubble departure radius increases as heat flux increases. At the same range of heat fluxes, chip $S$ shows a larger bubble departure radius compared with micro-pin-fins. As is well knows, the bubbles are generated and departure continuously from the heating surface in a steady state under the effects of buoyancy forces before entering the microgravity condition. However, after entering microgravity condition, due to weakening of buoyancy force, the vapor bubbles are generated and attach to the heater surface through a long time and then grow larger than that under terrestrial condition. Therefore, the average bubble departure radius in microgravity is much larger than that in normal gravity. Besides, for smooth surfaces at the heat fluxes of $7.5 \mathrm{~W} / \mathrm{cm}^{2}$ and $11.2 \mathrm{~W} / \mathrm{cm}^{2}$, only one bubble departed from the heater surface during the whole period in microgravity. For this reason, the standard deviation of average bubble departure radius is not marked out in Fig. 6. Compared to the smooth surface, the micro-pin-finned surface highly improves the number of vaporization cores, resulting in an increase of bubble number and a decrease of bubble size to enhance boiling heat transfer. In addition, it can be learned from the experiment results that the bubbles merge tempestuously on the heating surface especially at high heat fluxes [3]. Besides, the buoyancy becomes feeble and the merging of bubbles becomes more strenuous in microgravity. Due to the strong capillary force formed by micro-pin-fins, the fresh liquid can arrive on the heat surface for evaporation, and the bubbles still detach from the heater surface at a much higher heat flux than that from the smooth surface.

\section{Mathematical model}

\subsection{Traditional force balance model}

Karri's model [16] involved the buoyancy $F_{\mathrm{b}}$, surface tension $F_{\mathrm{s}}$, viscous drag $F_{\mathrm{d}}$, inertia force $F_{\mathrm{i}}$ and pressure difference $F_{\mathrm{p}}$. In addition, five well-known theoretical correlations were employed to predict the bubble departure radius. By using this model, the results of the bubble departure radius on smooth surface were in good agreement with the experimental micro-g data of Siegel and Keshock [13], and the working fluid is saturated steam water in Siegel and Keshock's experiment. However, for high subcooled boiling (30-43 K), the liquid temperature near the heater surface is higher than that far away from the heater surface. Therefore, a distinct temperature gradient for the liquid around the bubble is formed. Generally, surface tension decreases as temperature increases. Then Marangoni force $F_{\mathrm{M}}$ pulls the bubble to move towards the high temperature side, which prevents the bubble from

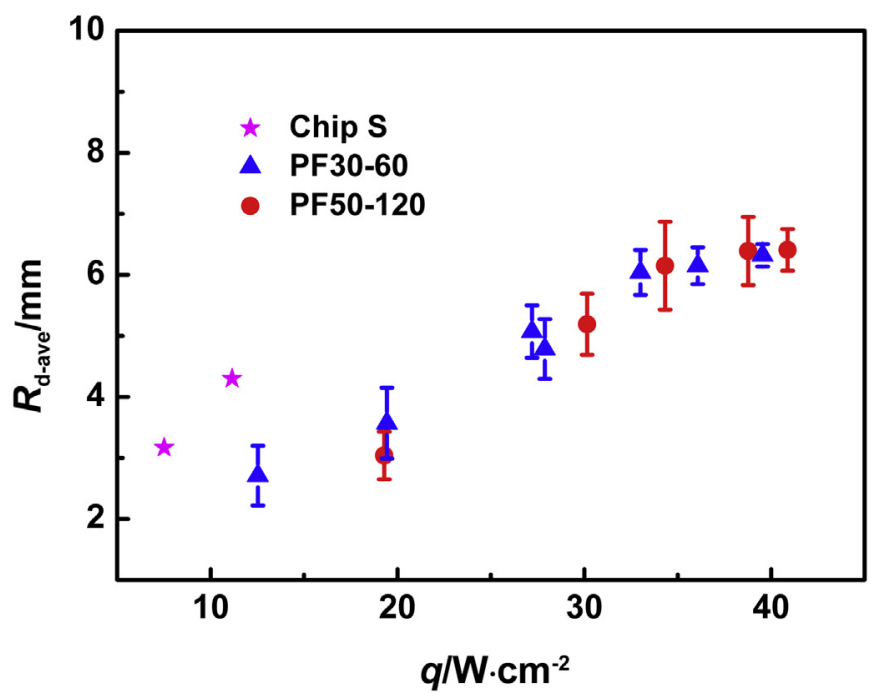

Fig. 6. Experimental data of average bubble departure radius of chip S, PF30-60 and PF50-120 under different heat fluxes in microgravity. 


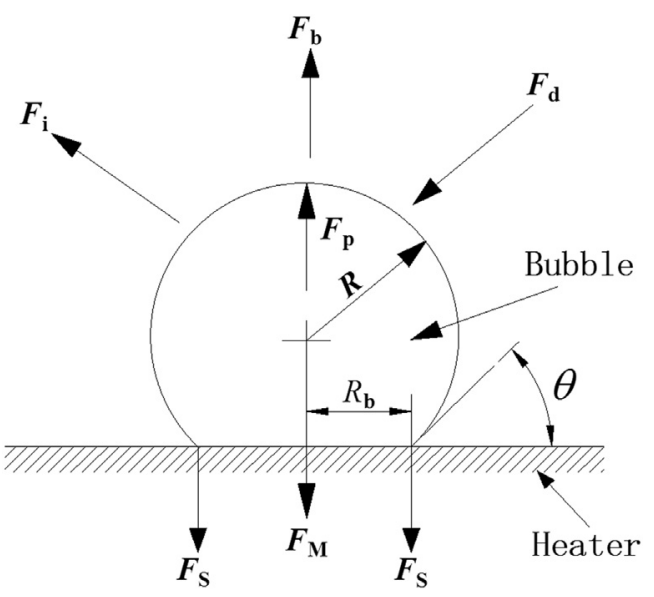

Fig. 7. Forces acting on a growing bubble.

departing from the heater surface. Thus, the opposite acting force-Marangoni force cannot be ignored. Cooper et al. [23] have shown that the bubble shape for water boiling in microgravity can be imaged as a truncated sphere when the Jakob number is not large. For most fluids in low flux nucleate boiling, this relation is approximately satisfied. Therefore, for simplicity, the bubble shape is imaged as a truncated sphere in the following discussions. The forces acting on a growing bubble are shown in Fig. 7, and the force balance of the bubble on the heating surface is described as the follow:

$F_{\mathrm{d}}+F_{\mathrm{S}}+F_{\mathrm{M}}=F_{\mathrm{b}}+F_{\mathrm{p}}+F_{\mathrm{i}}$

where $F_{M}$ was proposed by Zhang and Chao [24] and can be expressed as the follow:

$F_{\mathrm{M}}=\xi\left|\frac{\mathrm{d} \sigma}{\mathrm{d} T}\right| \Delta T_{\mathrm{Wb}} \pi R$

where $R$ and $\sigma$ denote the bubble radius and surface tension respectively. $\Delta T_{\mathrm{wb}}$ represents the temperature difference between the wall and the bulk liquid. In consideration of uncertainties in defining the shape of an evolving interface, empirical constants are invariably used to ensure that the model predictions match with

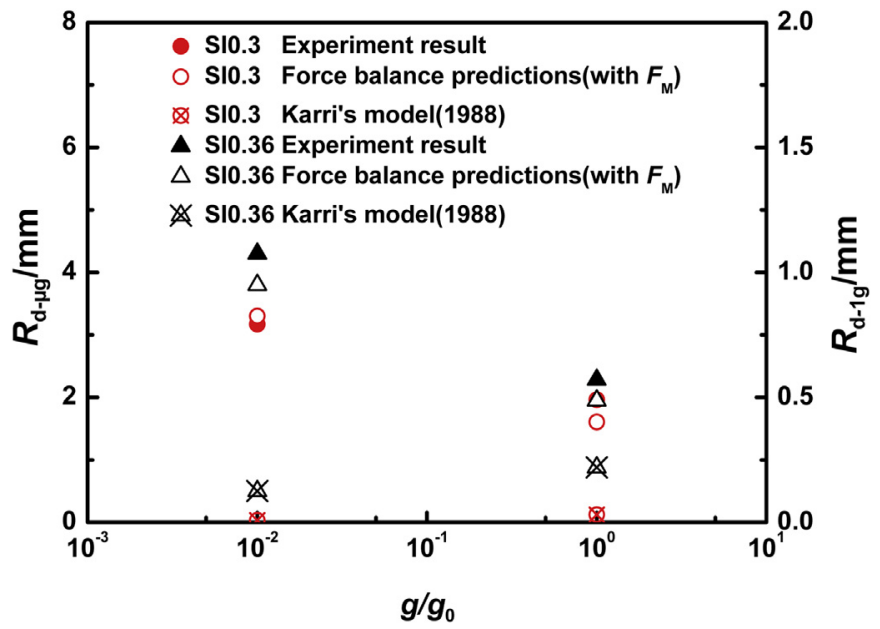

Fig. 8. Comparison of experimental results with force balance predictions in different gravity levels.
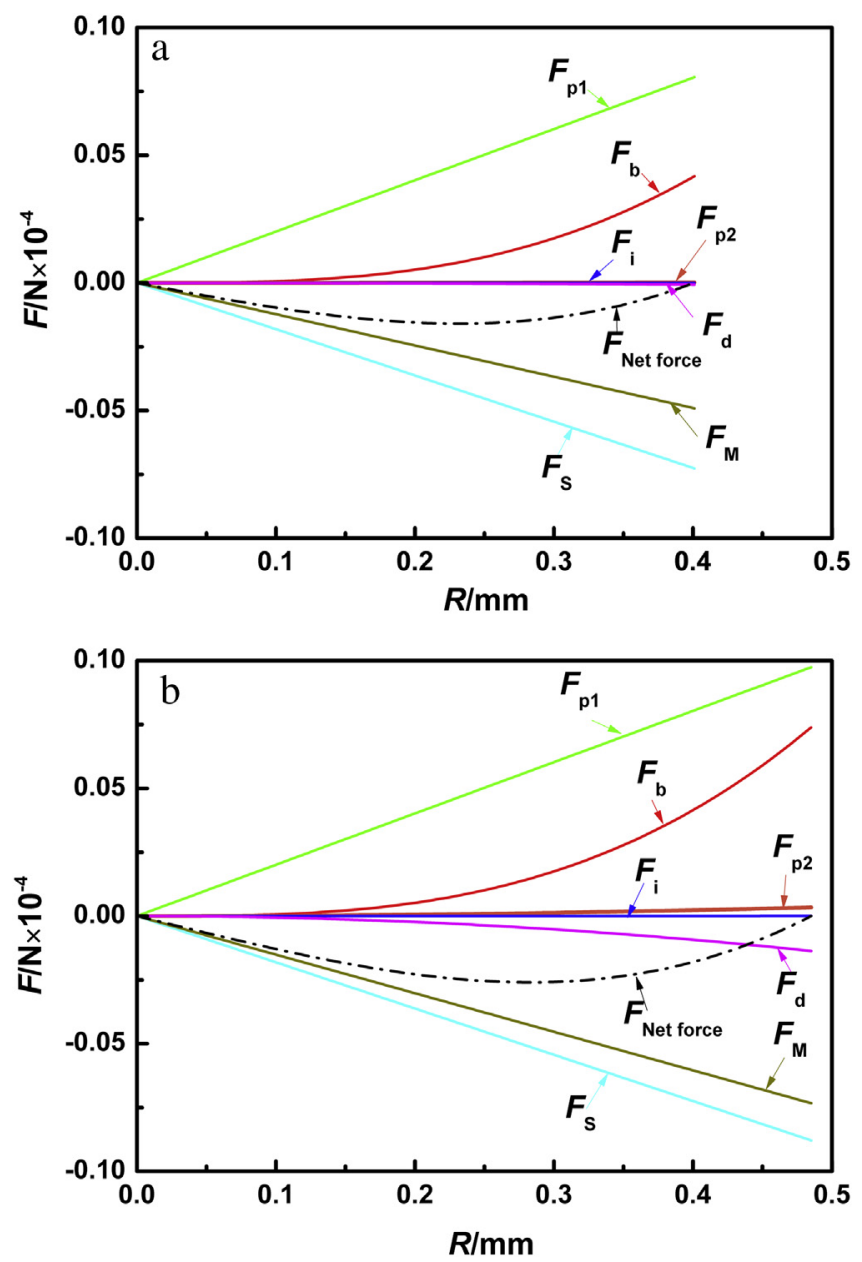

Fig. 9. Forces acting on a bubble growing in a subcooled FC-72 on smooth heating surface under $g / g_{0}=1$ (a) chip $S, I=0.30$ A (b) chip S, $I=0.36 \mathrm{~A}$.

data. This is especially true when force balance is made on a vapor bubble to determine the departure radius. Here, correction factor $\xi$ is 1 as determined by Zhang and Chao [24].

\subsection{Traditional prediction results of smooth surface}

Fig. 8 shows the comparison between measured bubble departure radius with force balance predictions in both normal gravity and microgravity. The working fluid in experiment is FC-72 under high subcooled condition, and Marangoni force is taken into consideration. In this figure, the predicted results of bubble departure radii for the two different heat fluxes of $7.5 \mathrm{~W} / \mathrm{cm}^{2}$ and $11.2 \mathrm{~W} / \mathrm{cm}^{2}$ in microgravity are $3.3 \mathrm{~mm}$ and $3.8 \mathrm{~mm}$ respectively, and the experimental statistical average values are $3.17 \mathrm{~mm}$ and $4.3 \mathrm{~mm}$ respectively, which means the errors between experimental results and theoretical prediction are $4.1 \%$ and $11.6 \%$. In normal gravity, the theoretical predictions of departure radii are $0.40 \mathrm{~mm}$ and $0.49 \mathrm{~mm}$ respectively, and the experimental statistical averages are $0.49 \mathrm{~mm}$ and $0.57 \mathrm{~mm}$ respectively, resulting in the errors of $18.4 \%$ and $14.0 \%$. These data indicate that traditional theoretical predictions are fairly close to the experimental results. On the contrary, the predictions of departure radii by Karri's model are $0.032 \mathrm{~mm}$ and $0.5 \mathrm{~mm}$ in microgravity resulting in the errors of $99.0 \%$ and $88.4 \%$, and $0.031 \mathrm{~mm}$ and $0.22 \mathrm{~mm}$ in normal gravity resulting in the errors of $93.7 \%$ and $61.4 \%$, respectively. Thus, Karri's force balance model without Marangoni force $F_{\mathrm{M}}$ cannot predict 
bubble departure radii of our high subcooled boiling heat transfer experiment well in both normal gravity and microgravity. In the calculations, the contact angle $\theta$ is $39.5^{\circ}$ and the gravitational acceleration is about $10^{-2} g_{0}$.

Fig. 9(a) and (b) shows the forces acting on a bubble versus the radii of the bubbles at the two different heat fluxes of $7.5 \mathrm{~W} / \mathrm{cm}^{2}$ and $11.2 \mathrm{~W} / \mathrm{cm}^{2}$, respectively, in normal gravity. It is shown that the inertial $F_{\mathrm{i}}$, drag $F_{\mathrm{d}}$, excess vapor pressure force $F_{\mathrm{p} 2}$ are essentially constant for all bubble radius, and the values of these three forces are quite small. Besides, positive buoyancy force acting on the bubble is not great enough when the bubble is in small radius. As a result, the increase in excess capillary pressure $F_{\mathrm{p} 1}$ alone is insufficient to overcome the growing surface tension forces $F_{S}$ and Marangoni force $F_{\mathrm{M}}$. Thus, the bubble continues to grow under negative forces on the heater surface, and buoyancy force $F_{\mathrm{b}}$ increases during this process. When the total net force $F_{\text {net-force, }}$ the sum of positive and negative forces, changes from negative to positive, the bubble begins to detach from the heater surface. However, the wall temperature of smooth chip increases with increasing heat flux which leads to larger Marangoni force acting on the bubble at heat flux of $11.2 \mathrm{~W} / \mathrm{cm}^{2}$. Hence, the bubble departure radius of $11.2 \mathrm{~W} / \mathrm{cm}^{2}$ is larger than that of $7.5 \mathrm{~W} / \mathrm{cm}^{2}$.

Fig. 10(a) and (b) shows the forces acting on a bubble versus the radii of the bubbles at the two different heat fluxes of $7.5 \mathrm{~W} / \mathrm{cm}^{2}$ and $11.2 \mathrm{~W} / \mathrm{cm}^{2}$, respectively, in microgravity. It can be clearly seen that vapor bubbles experience a very remarkable change of bubble
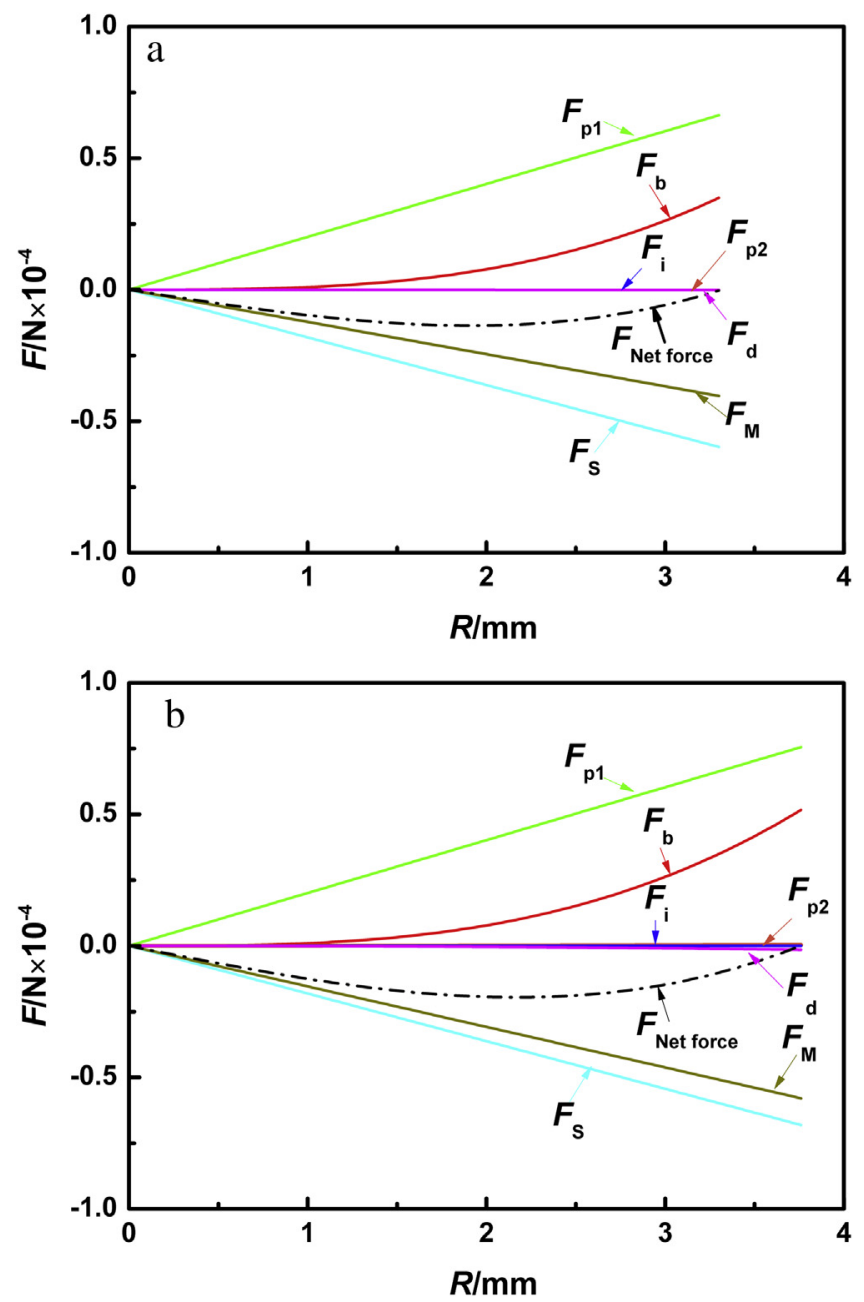

Fig. 10. Forces acting on a bubble growing in a subcooled FC-72 on smooth heating surface under $g / g_{0}=0.01$ (a) chip $\mathrm{S}, I=0.30 \mathrm{~A}$ (b) chip $\mathrm{S}, I=0.36 \mathrm{~A}$. departure radius with reducing gravity. The bubble departure radius becomes much larger than that in normal gravity. It is also worth noting that excess capillary pressure $F_{\mathrm{p} 1}$, the buoyancy force $F_{\mathrm{b}}$, surface tension force $F_{\mathrm{S}}$ and Marangoni force $F_{\mathrm{M}}$ play important roles in determining bubble detachment. Thus, the total net force is influenced by acceleration of gravity, physical properties of the working fluid, wall superheat and liquid subcooling. As mentioned above, for the heat flux of $14.8 \mathrm{~W} / \mathrm{cm}^{2}$, a coalesced large bubble forms quickly and tends to maintain a hemispherical dome shape with a large contact area on the heater surface, causing continuous increase in wall temperature. As increasing wall superheat strengthens the negative force $F_{\mathrm{M}}$ significantly, it is very difficult for the bubble to detach from the heater surface. Besides, over time, the full coverage of the large bubble on the heater surface prevents the fresh bulk liquid from accessing the heating surface for evaporation heat transfer, making the removal of heat flux very difficult and leading to further obvious increase of the mean heater surface temperature and strengthening negative forces. As a result, deterioration of boiling heat transfer occurred.

Comparison of experimental results with predictions of chip $\mathrm{S}$ and micro-pin-finned surfaces by the force balance model is shown in Fig. 11. It can be observed that our force balance model considering Marangoni force can predict bubble departure radius well for both chip $S$ and micro-pin-fins under microgravity condition in the low heat flux region, but cannot predict bubble departure radius well for the micro-pin-fins' case at high heat fluxes. It predicts much smaller radii compared to the actual value at high heat fluxes. Furthermore, the monotonous increase of bubble departure radius with heat flux cannot be captured qualitatively. The reason is attributed to that bubble merging is ignored during the calculation in the high heat flux region. In fact, merging of bubbles is not very intensely at low heat fluxes but very vigorous for the bubble departure from the micro-pin-finned surface at high heat fluxes. By using the new force balance model, the prediction values of the bubble departure radius of micro-pin-fins are all about $3 \mathrm{~mm}$. It indicates that the bubble should depart from the heater surface when the bubble radius is larger than $3 \mathrm{~mm}$. However, bubble coalescence in vertical and horizontal directions become more intensely at high heat fluxes, and thus delays the bubble detachment. In this process, the total net force $F_{\text {net-force }}>0$. The primary bubble grows larger gradually and there are a lot of smaller bubbles around the primary bubble as shown in Fig. 12(a). The thermocapillary flow can drive the bubbles staying on the top of the micro-

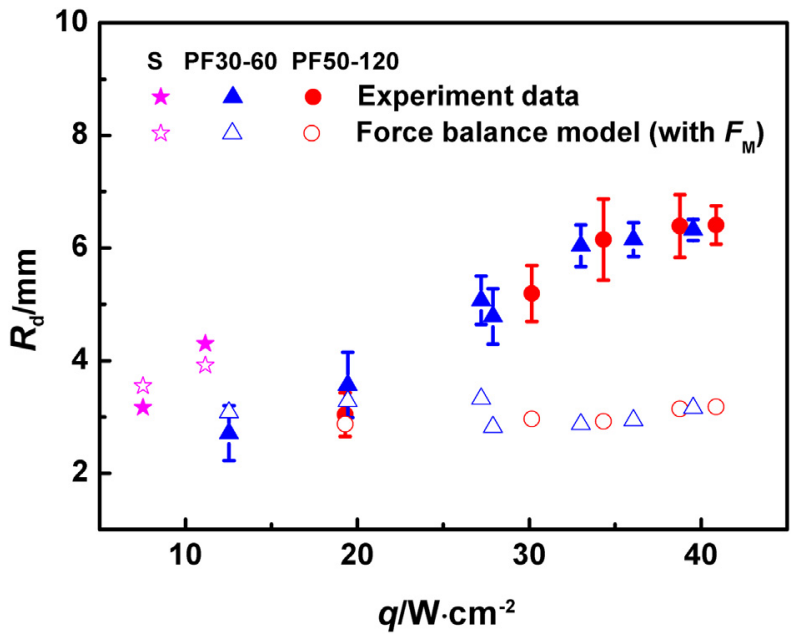

Fig. 11. Comparison of experimental results with predictions by force balance model considering $F_{\mathrm{M}}$. 

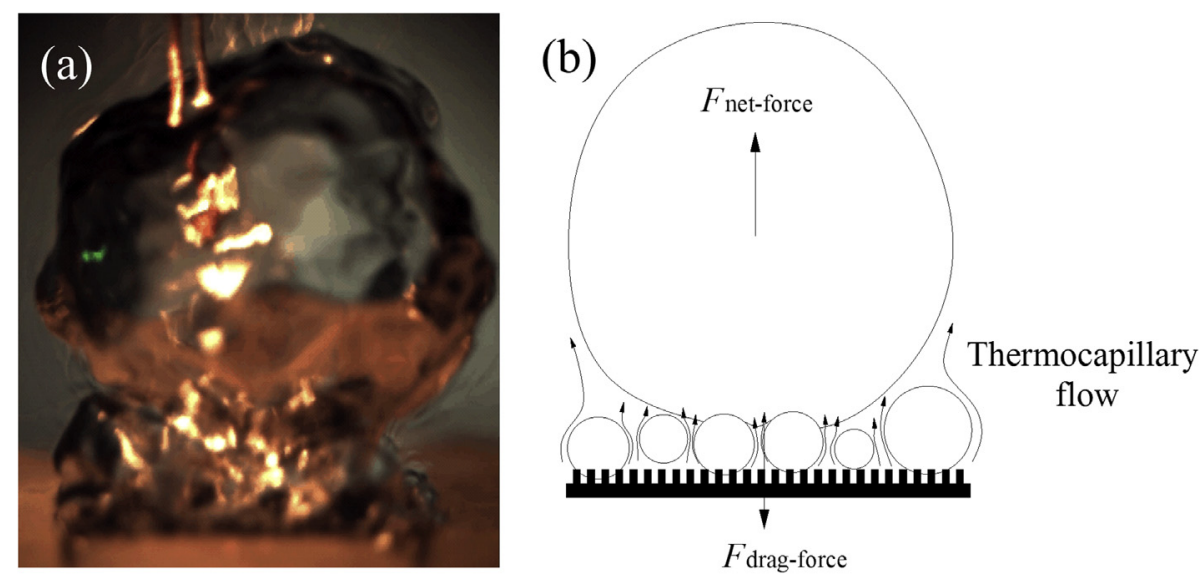

Fig. 12. (a) Bubble behavior before departure of PF30-60 at $q=36.1 \mathrm{~W} \mathrm{~cm}^{-2}$ (b) Schematic diagram of the mechanism of thermocapillary flow.

pin-fins to coalesce with the primary bubble as shown in Fig. 12(b). Therefore, the small bubbles form connections between the primary bubble and the heated surface to prevent the primary bubble from departing, resulting an additional equivalent drag force $F_{\text {drag- }}$ force acting on the primary bubble. At the beginning of bubble coalescence, $F_{\text {net-force }}-F_{\text {drag-force }}<0$, thus the primary coalesced bubble cannot depart from the heater surface. As primary bubble grows larger gradually mainly by absorbing small bubbles, $F_{\text {net-force }}$ also becomes larger. Until the total net force acting on the primary bubble is large enough to overcome the additional drag force by small bubbles, $F_{\text {net-force }}-F_{\text {drag-force }}>0$, the primary bubble can depart from the heater surface. Hence, a new bubble dynamic model for micro-pin-finned surfaces is suggested. In this model, bubble departure radius is influenced by bubble force balance at low heat fluxes and by bubble merging at high heat fluxes. The evaporation at the bottom of merged bubbles enlarges the bubbles.

\subsection{Bubble merged model}

Bubble dynamics includes bubble growth, bubble merger and bubble departure processes. In the past, these subprocesses have been treated disjointedly as models and the correlations have been developed for either one of them. In fact, there is a continuous feedback among several subprocesses occurring simultaneously. In our model, the bubble radius caused by merged bubbles can be calculated through the following steps. Firstly, the other part of the superheated fluid evaporating in the unit area during per time unit makes the bubble growing. Secondly, in our study, the bubbles converged on the heating surface have continuously fluid supply, and there are lots of small bubbles absorbed by bigger bubbles because of the microstructure channel. The horizontal-and-vertical fierce merger causes a further increase in bubble departure radius. Due to all the factors above, the evaporation mass of working fluid FC-72 on $1 \mathrm{~m}^{2}$ chip surface per time unit is expressed as follows:

$m=\frac{Q}{\left(c_{\mathrm{p}}\left(T_{\mathrm{sat}}-T_{\mathrm{b}}\right)+h_{\mathrm{fg}}\right)}$

where $Q$ can be expressed as below:

$Q=A q$

where $A$ represents heat transfer area $\left(\mathrm{m}^{2}\right), c_{\mathrm{p}}$ is specific heat capacity $\left(\mathrm{J} \mathrm{kg}^{-1} \mathrm{~K}^{-1}\right)$, and $h_{\mathrm{fg}}$ represents the liquid's latent heat of vaporization $\left(\mathrm{kJ} \mathrm{kg}^{-1}\right)$.
The vapor from evaporation including the diffusive vapor caused by convection and the gas will not get into the bubble to make it larger. Straub [25] have reported that the evaporation of working fluid per area unit and per time unit have a linear increase with the increase of heat flux at a given liquid subcooling. Thus, we assumed that the vapor mass from evaporation includes the diffusive vapor caused by convection and the gas have a linear increase with total evaporation mass of working fluid. Based on mass conservation law, the mass of vapor produced during per time unit is expressed as follows:

$m=\rho_{\mathrm{v}} V n+\alpha m+b$

where $\alpha$ represents the proportion of the vapor from evaporation including the diffusive vapor caused by convection and the gas. $b$ is constant. $\rho_{\mathrm{v}}$ stands for the FC-72 vapor density $\left(\mathrm{kg} \mathrm{m}^{-3}\right)$. $V$ indicates the volume $\left(4 \pi / 3 R_{\mathrm{d}-\mathrm{a}}^{3} / \mathrm{m}^{3}\right)$ of the big bubble before its departure. $n$ represents the departure frequency of bubbles. Under microgravity, the departure frequency of bubbles become much lower compared with that in normal gravity. Video of the bubble behavior which was obtained by using a high speed digital camera imaging 500 frames per second at a resolution of $1024 \times 640$ pixels was saved as BMP format. Thus, we can find the image which the bubble is detaching from the heater surface exactly. Here, we could count the number of departure bubbles in $3 \mathrm{~s}$ after entering microgravity environment, and then calculate the departure frequency of bubbles which is shown in Table 4. From Table 4, we can find that the bubble departure frequency is nearly the same with each other at moderate and high heat fluxes. On one hand, with increasing heat flux, the evaporation mass of working fluid increases, and it should make the primary bubble growth and departure quickly, on the other hand, high heat fluxes can also produce much more small bubbles around the primary bubble which make a drag force acting on the primary bubble and delay the primary bubble departure. As

Table 4

Experimental result of parameter $n$ in microgravity.

\begin{tabular}{llllll}
\hline Run\# & $\begin{array}{l}\text { Heat flux } \\
q\left(\mathrm{~W} \mathrm{~cm}{ }^{-2}\right)\end{array}$ & $n\left(\mathrm{~s}^{-1}\right)$ & Run\# & $\begin{array}{l}\text { Heat flux } q \\
\left(\mathrm{~W} \mathrm{~cm}^{-2}\right)\end{array}$ & $n\left(\mathrm{~s}^{-1}\right)$ \\
\hline PF3060-0.34A & 12.5 & 1.00 & PF50120U48 & 19.3 & 3.33 \\
PF3060-0.42A & 19.4 & 2.33 & PF50120U60 & 30.2 & 3.33 \\
PF3060-0.50A & 27.2 & 2.33 & PF50120U64 & 34.3 & 3.00 \\
PF3060-55V & 27.9 & 2.33 & PF50120U68 & 38.8 & 3.00 \\
PF3060-60V & 33.0 & 2.33 & PF50120U70 & 40.9 & 3.00 \\
PF3060-63V & 36.1 & 2.33 & & & \\
PF3060-68V & 39.5 & 2.33 & & & \\
\hline
\end{tabular}


a result, the bubble departure frequency is nearly the same with each other at moderate and high heat fluxes.

In fact, for micro-pin-fins, there is only little bubble coalescence at low heat fluxes. Therefore, the traditional force balance model can be employed to predict bubble departure radius with a small error at low heat fluxes, as shown in Fig. 11. Thus, we choose the two low heat fluxes points $\left(q=12.5 \mathrm{~W} \mathrm{~cm}^{-2}, q=19.4 \mathrm{~W} \mathrm{~cm}^{-2}\right)$ as the given conditions, and the force balance predictions of departure radius $R_{\mathrm{d}-0.34}$ and $R_{\mathrm{d}-0.42}$ can be used to calculate the factors $\alpha$ and $b$, the equations of which can be expressed as:

$(1-\alpha) m_{0.34}=\rho_{\mathrm{v}} \frac{4 \pi R_{\mathrm{d}-0.34}^{3}}{3} n_{0.34}+b$

$(1-\alpha) m_{0.42}=\rho_{\mathrm{v}} \frac{4 \pi R_{\mathrm{d}-0.42}^{3}}{3} n_{0.42}+b$

By solving the equations from (9) to (10), the result can be obtained as follows:

$m=\rho_{\mathrm{v}} V n+0.942 m+4.1 \times 10^{-6}$

Thus, the merger caused departure radius $R_{\mathrm{d}-\mathrm{a}}$ can be expressed as below:

$R_{\mathrm{d}-\mathrm{a}}=\sqrt[3]{\frac{3 m(1-\alpha)-b}{4 \rho_{\mathrm{v}} n \pi}}$

Fig. 13 illustrates the comparison of experimental values with predictions by force balance model and bubble merged model (using Eqs. (11) and (12)) for micro-pin-finned surfaces. In this figure, the predicted results of bubble departure radii for PF30-60 at seven different heat fluxes in microgravity are $3.08 \mathrm{~mm}, 3.28 \mathrm{~mm}$, $3.97 \mathrm{~mm}, 4.31 \mathrm{~mm}, 4.62 \mathrm{~mm}, 4.90 \mathrm{~mm}$ and $4.97 \mathrm{~mm}$, respectively, and the experimental statistical average values are $2.71 \mathrm{~mm}$, $3.57 \mathrm{~mm}, 5.07 \mathrm{~mm}, 4.78 \mathrm{~mm}, 6.04 \mathrm{~mm}, 6.15 \mathrm{~mm}$ and $6.32 \mathrm{~mm}$, respectively, which means the errors between experiment and theoretical prediction are 20.3\%, 8.1\%, 21.8\%, 9.9\%, 23.4\%, 20.3\% and $21.3 \%$ respectively. For PF50-120, the predicted results are $3.16 \mathrm{~mm}$, $3.91 \mathrm{~mm}, 4.34 \mathrm{~mm}, 4.58 \mathrm{~mm}$ and $4.74 \mathrm{~mm}$, respectively, and the experimental statistical average values are $3.04 \mathrm{~mm}, 5.19 \mathrm{~mm}$, $6.35 \mathrm{~mm}, 6.39 \mathrm{~mm}$ and $6.41 \mathrm{~mm}$, respectively, which means the errors between experiment and theoretical prediction are $3.8 \%$, $24.5 \%, 27.2 \%, 28.4 \%$ and $26.1 \%$ respectively. Therefore, it can be

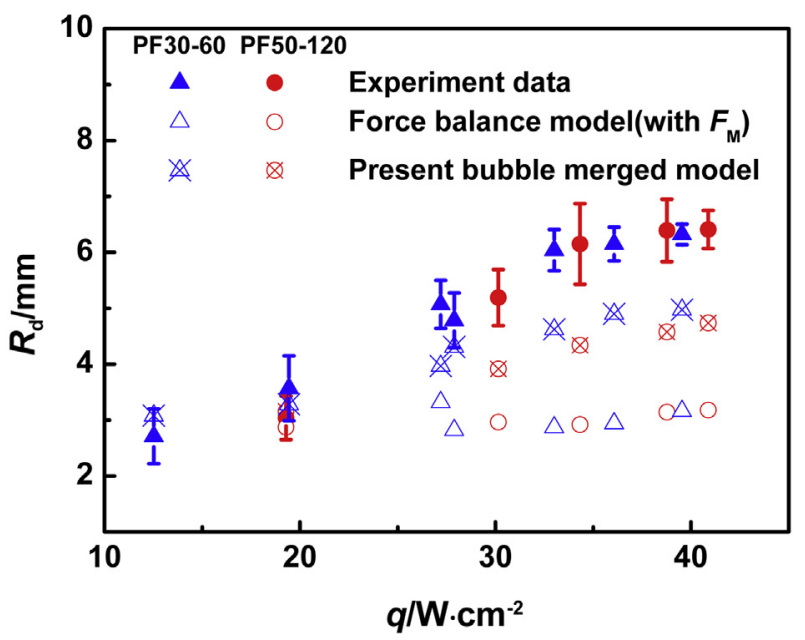

Fig. 13. Comparison of experimental results with predictions by force balance model and bubble merged model in microgravity.

concluded that the experimental values and predictions obtained by adopting the modified model are in similar growth trend. Here, for the bubble merged model, tempestuous coalesces of the bubbles on the micro-pin-finned surface at both moderate and high heat fluxes are considered. Therefore, bubble merger model can be used to predict bubble growth much better than the force balance model at moderate and high heat fluxes.

\section{Conclusions}

Nucleate boiling heat transfers of gas-saturated FC-72 on smooth surface and micro-pin-finned surface are experimentally investigated in microgravity environment by utilizing the drop tower facility in Beijing. The experimental data are presented for the bubble departure radius of gas-saturated FC-72 over a wide range of heat fluxes. The model for predicting bubble departure radius in microgravity is studied. The main conclusions are itemized as follows:

Micro-pin-fins still show a large enhancement on boiling heat transfer compared with smooth surface in microgravity. The force balance model considering Marangoni Force $F_{\mathrm{M}}$ can be used to well predict the bubble departure radius for the smooth surface. It is also worth noting that excess capillary pressure $F_{\mathrm{p} 1}$, the buoyancy force $F_{\mathrm{b}}$, surface tension forces $F_{\mathrm{S}}$ and Marangoni force $F_{\mathrm{M}}$ play important roles in determining bubble detachment, and these forces are influenced by acceleration of gravity, physical properties of the working fluid, wall superheat and liquid subcooling.

The traditional force balance model can be used to well predict the bubble departure radius for micro-pin-finned surface at low heat fluxes, but not suitable for the prediction for that involves micro-pin-finned surface due to tempestuous coalesces of the bubbles at high heat fluxes. A new bubble merged model of bubble departure radius for the micro-pin-finned surface was proposed. The bubble departure radii of the micro-pin-finned surface predicted by adopting the bubble merged model agree much better with the experimental data than the force balance model.

\section{Acknowledgements}

This work is supported by the project of National Natural Science Foundation of China (no. 51225601) and the Key Laboratory of Microgravity/CAS for experiments utilizing the drop tower Beijing.

\section{Nomenclature}

A

b

$c_{\mathrm{p}}$

F

$F_{\mathrm{b}}$

$F_{\mathrm{d}}$

$F_{\mathrm{i}}$

$F_{\mathrm{M}}$

$F_{\mathrm{p}}$

$F_{\mathrm{p} 1}$

$F_{\mathrm{p} 2}$

$F_{\mathrm{s}}$

$F_{\text {net-force }}$

$g$

$g_{0}$

$h_{\mathrm{fg}}$

I

$m$ heat transfer area, $\mathrm{m}^{2}$

constant

specific heat capacity, $\mathrm{J} \mathrm{kg}^{-1} \mathrm{~K}^{-1}$

force, $\mathrm{N}$

buoyancy force, $\mathrm{N}$

drag force, $\mathrm{N}$

inertia force, $\mathrm{N}$

Marangoni force, $\mathrm{N}$

pressure force, $\mathrm{N}$

excess capillary pressure force, $\mathrm{N}$

dynamic excess vapor pressure force, $\mathrm{N}$

surface tension force, $\mathrm{N}$

net force, $\mathrm{N}$

gravitational acceleration at the microgravity condition, $\mathrm{m} \mathrm{s}^{-2}$ gravitational acceleration at the terrestrial condition, $\mathrm{m} \mathrm{s}^{-2}$

liquid's latent heat of vaporization, $\mathrm{kJ} \mathrm{kg}^{-1}$

heating current, $A$

mass of vapor produced during per time unit, $\mathrm{kg}$ 
$n \quad$ departure frequency of bubbles, $\mathrm{s}^{-1}$

$P_{\mathrm{S}} \quad$ the system total pressure, $\mathrm{Pa}$

$Q \quad$ heat input, $W$

$q \quad$ heat flux, $\mathrm{W} \mathrm{cm}^{-2}$

$R \quad$ bubble radius, $\mathrm{mm}$

$R_{\mathrm{b}} \quad$ bubble base radius, $\mathrm{mm}$

$R_{\mathrm{d}} \quad$ bubble departure radius, $\mathrm{mm}$

$R_{\mathrm{d}-\mathrm{a}} \quad$ merger caused accessorial radius, $\mathrm{mm}$

$R_{\mathrm{d}-a v e} \quad$ experimental statistical average bubble radius, $\mathrm{mm}$

$T_{\mathrm{b}} \quad$ temperature of bulk liquid, ${ }^{\circ} \mathrm{C}$

$T_{\text {sat }} \quad$ saturation temperature, ${ }^{\circ} \mathrm{C}$

$T_{\mathrm{w}} \quad$ wall temperature, ${ }^{\circ} \mathrm{C}$

$\Delta T_{\text {sat }} \quad$ wall superheat $=T_{\mathrm{w}}-T_{\text {sat }}, \mathrm{K}$

$\Delta T_{\text {sub }} \quad$ liquid subcooling $=T_{\mathrm{sat}}-T_{\mathrm{b}}, \mathrm{K}$

$\Delta T_{\mathrm{wb}} \quad$ temperature difference between wall and bulk

liquid $=T_{\mathrm{w}}-T_{\mathrm{b}}, \mathrm{K}$

$U \quad$ heating voltage, $\mathrm{V}$

$V \quad$ volume of the big bubble before its departure, $\mathrm{m}^{3}$

$\alpha \quad$ the proportion of the vapor from evaporation including the diffusive vapor caused by convection and the gas

$\theta \quad$ contact angle, degree

$\rho_{\mathrm{V}} \quad$ vapor density, $\mathrm{kg} \mathrm{m}^{-3}$

$\sigma \quad$ surface tension, $\mathrm{N} \mathrm{m}^{-1}$

\section{References}

[1] M.Z. Yuan, J.J. Wei, Y.F. Xue, J.B. Fang, Subcooled flow boiling heat transfer of FC-72 from silicon chips fabricated with micro-pin-fins, Int. J. Therm. Sci. 48 (2009) 1416-1422.

[2] J.J. Wei, J.F. Zhao, Y.F. Xue, M.Z. Yuan, Boiling heat transfer enhancement by using micro-pin-finned surface for electronics cooling, Microgravity Sci, Technol. 21 (2009) 159-173.

[3] J.J. Wei, Y.F. Xue, J.F. Zhao, J. Li, Bubble behavior and heat transfer of nucleate pool boiling on micro-pin-finned surface in microgravity, Chin. Phys. Lett. 28 (2011) 016401-1-016401-4.

[4] Y.F. Xue, J.F. Zhao, J.J. Wei, Y.H. Zhang, B.J. Qi, Experimental study of nucleate pool boiling of FC-72 on micro-pin-finned surface under microgravity, Int. J. Heat Mass Transfer 63 (2013) 425-433.

[5] W. Fritz, W. Ende, Berechnung des maximalvolumens von dampfslasen, Phys. Z. 36 (1935) 379-384.
[6] P.W. Mcfadden, P. Grassmann, The relation between bubble frequency and diameter during nucleate pool boiling, Int. J. Heat Mass Transfer 5 (1962) $169-173$.

[7] R. Cole, W.M. Rohsenow, Correlation of bubble departure diameters for boiling of saturated liquids, Chem. Eng. Prog. Symp. Ser. 65 (1966) 211-213.

[8] R. Cole, H.L. Shulman, Bubble growth rates at high Jakob numbers, Int. J. Heat Mass Transfer 9 (1966) 1377-1399.

[9] R. Cole, Bubble frequencies and departure volumes at subatmospheric pressures, AIChE J. 13 (1967) 779-783.

[10] D. Gorenflo, V. Knabe, V. Beiling, Bubble density on surfaces with nucleate boiling-its influence on heat transfer, in: Proc. 8th International Heat Transfer Conference, San Fransisco, vol. 4, 1986, pp. 1995-2000.

[11] L.Z. Zeng, J.F. Klausner, R. Mei, A unified model for the prediction of bubble detachment diameters in boiling systems. Part 1: pool boiling, Int. J. Heat Mass Transfer 36 (1993) 2261-2270.

[12] C. Yang, Y. Wu, X. Yuan, C. Ma, Study on bubble dynamics for pool nucleate boiling, Int. J. Heat Mass Transfer 43 (2000) 203-208.

[13] R. Siegel, E.G. Keshock, Effects of reduced gravity on nucleate boiling bubble dynamics in saturated water, AIChE J. 10 (1964) 507-517.

[14] G. Keshock, R. Siegel, Forces acting on bubbles in nucleate boiling bubble dynamics in saturated water, NASA Tech. (1964). Note, TN D-2299.

[15] N. Zuber, Hydrodynamic Aspects of Boiling Heat Transfer, University of California, Los Angeles, 1959.

[16] S. Karri, Dynamics of bubble departure in micro-gravity, Chem. Eng. Commun. 70 (1) (1988) 127-135.

[17] D.J. Lee, Bubble departure radius under microgravity, Chem. Eng. Commun. 117 (1992) 175-189.

[18] J.F. Zhao, G. Liu, S.X. Wan, N. Yan, Bubble dynamics in nucleate pool boiling on thin wires in microgravity, Microgravity Sci. Technol. 20 (2008) 81-89.

[19] J.J. Wei, H. Honda, Effects of fin geometry on boiling heat transfer from silicon chips with micro-pin-fins immersed in FC-72, Int. J. Heat Mass Transfer 46 (2003) 4059-4070.

[20] H. Honda, J.J. Wei, Enhanced boiling heat transfer from electronic components by use of surface microstructures, Exp. Therm. Fluid. Sci. 28 (2004) 159-169.

[21] Y.F. Xue, J.F. Zhao, J.J. Wei, J. Li, D. Guo, S.X. Wan, Experimental study of nucleate pool boiling of FC-72 on smooth surface under microgravity, Microgravity Sci. Technol. 23 (2011) S75-S85.

[22] J.J. Wei, L.J. Guo, H. Honda, Experimental study of boiling phenomena and heat transfer performances of FC-72 over micro-pin-finned silicon chips, Heat Mass Transfer 41 (2005) 744-755.

[23] M.G. Cooper, A.M. Judd, R.A. Pike, Shape and departure of single bubble growing at a wall, in: Proceedings of the Sixth International Heat Transfer Conference, 1, Toronto, Canada, 1978, p. 155.

[24] N.L. Zhang, D.F. Chao, Models for enhanced boiling heat transfer by unusua Marangoni effects under microgravity conditions, Int. Commun. Heat Mass Transfer 26 (1999) 1081-1090.

[25] J. Straub, Boiling heat transfer and bubble dynamics in microgravity, Adv. Heat Transfer 35 (2001) 57-172. 